\title{
Exploração de energia maremotriz para geração de eletricidade: aspectos básicos e principais tendências
}

\author{
Exploring tidal energy for electricity generation: basic issues and main trends \\ Pedro Bezerra Leite Neto ${ }^{1} \quad$ Osvaldo Ronald Saavedra $^{1} \quad$ Nelson José Camelo $^{1}$ \\ Luiz A. de Souza Ribeiro ${ }^{1} \quad$ Rafael M. Ferreira ${ }^{2}$ \\ Recibido 15 de noviembre de 2010, aceptado 16 de mayo de 2011 \\ Received: November 15, $2010 \quad$ Accepted: May 16, 2011
}

\begin{abstract}
RESUMEN
A exploração da energia das marés tem se tornado cada vez mais atrativa em diversos aspectos. Alguns projetos maremotrizes sinalizam que outros projetos de geração de energia futuros podem levar em consideração esta alternativa tecnológica. Portanto, neste trabalho são apresentados os princípios básicos de exploração da energia maremotriz, as principais tecnologias utilizadas e princípios de operação de uma usina maremotriz. Além disso, são destacados alguns aspectos importantes, tais como ambientais e econômicos, que estão envolvidos neste tipo de geração e que precisam ser considerados. É feita ainda uma breve avaliação de alguns dos principais projetos já existentes e também são apresentadas algumas das novas tecnologias e as principais tendências em termos de geração maremotriz. Finalmente, são apresentados alguns dos locais mais adequados para a exploração da energia maremotriz no Brasil, bem como algumas das propostas que podem viabilizar tais aproveitamentos.
\end{abstract}

Palabras clave: Energias renováveis, energia maremotriz, correntes de marés, geração de energia elétrica, eficiência energética.

\begin{abstract}
Tidal energy exploration has become more attractive under diverse aspects. Some tidal operating projects show that other new similar energy generation projects may consider this find of technology. Therefore, some basic principles of tidal energy exploration, main technologies and operating modes of a tidal power plant, are presented in this work. Moreover, some important aspects, such as environmental and economic aspects involved in this kind of energy generation, must be considered, and are addressed in this work. A brief evaluation of some existing projects has been made and some new technologies and main tendencies in tidal power generation are revised. Finally, some of the most adequate places for tidal generation in Brazil are presented, as well as some of proposals that may make feasible such exploitations.
\end{abstract}

Keywords: Renewable energy, tidal energy, tidal current, power generation, power efficiency.

\section{INTRODUÇÃO}

A crescente demanda por energia associada ao curto horizonte dos combustíveis fósseis, bem como os aspectos ambientais relacionados ao consumo destes, tem desafiado o setor energético mundial a buscar novas fontes energéticas, sendo algumas destas bastante promissoras e relativamente recentes.

Os mares constituem uma fonte energética bastante promissora e, portanto, sua exploração não é recente. Registros históricos apontam o uso de moinhos

\footnotetext{
1 Instituto de Energia Elétrica. Universidade Federal do Maranhão. 65080-040. São Luís, Brasil. E-mail: pedroblneto@yahoo.com.br; o.saavedra@ieee.org; ncamelo@dee.ufma.br; luiz_ribeiro@dee.ufma.br

2 Laboratório de Tecnologia Submarina. Universidade Federal do Rio de Janeiro. 21945-970. Rio de Janeiro, Brasil. E-mail: rafael@1ts.coppe.ufrj.br
} 
movidos a marés (ou maremotrizes) por habitantes da costa do Atlântico Norte até, pelo menos, durante o início da Idade Média [1].

Atualmente, a energia proveniente dos mares tem sido explorada principalmente para a geração de eletricidade. Estima-se que o potencial energético global seja da ordem de 500 a $1.000 \mathrm{TWh} / \mathrm{ano}$ [2]. Embora seja um valor significativo, apenas alguns poucos lugares do mundo possuem amplitudes de marés significativas, além de outras condições geográficas adequadas a este tipo de exploração. Na Figura 1 são mostrados os principais locais do planeta onde os aproveitamentos maremotrizes são mais apropriados.

Um dos locais de maior destaque em termos de potencial extraível é o Reino Unido, onde se estima cerca de $18 \mathrm{TW} / \mathrm{h}$ em aproveitamentos disponíveis [3], ou ainda alguns locais na América do Sul, como a costa norte do Brasil ou o Chile, por exemplo, onde neste último estima-se um potencial extraível de pelo menos $500 \mathrm{MW}$ [4].

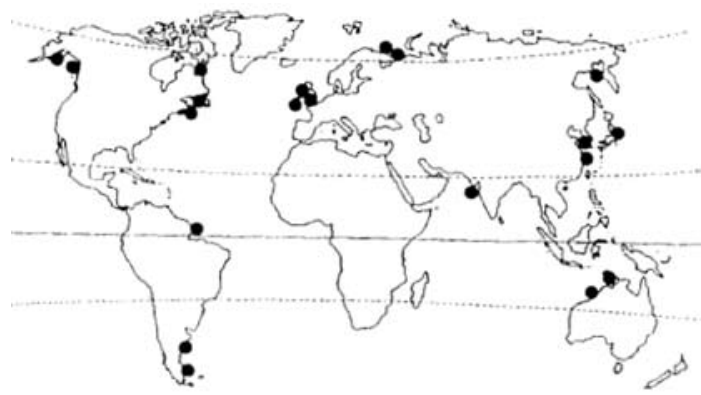

Figura 1. Principais locais no mundo onde as marés são mais adequadas para a sua exploração [2].

O enorme potencial energético global aliado aos avanços nas tecnologias de aproveitamentos maremotrizes, tem tornado esta alternativa energética bastante atrativa inclusive sob o ponto de vista econômico.

Portanto, neste trabalho é feita uma síntese das principais características associadas à exploração maremotriz: aspectos técnicos, econômicos e ambientais, bem como as principais tendências e novas tecnologias. Além disso, são feitas algumas considerações sobre dois estudos de caso: a barragem do Bacanga e a baía de Turiaçu, ambas no estado do Maranhão - Brasil.

\section{FENÔMENOS ASSOCIADOS ÀS MARÉS}

Um dos principais problemas relacionados às fontes alternativas de energia está na intermitência, associada à dificuldade de previsibilidade, ou seja, além da fonte primária não ser constante, existe ainda a dificuldade de se prever exatamente em que momento esta estará disponível, como ocorre com a energia eólica, por exemplo.

Embora a energia maremotriz também seja intermitente, esta possui a grande vantagem de ser previsível, ou seja, é possível conhecer em que momento e em que quantidade uma usina maremotriz poderá produzir energia. Isto se deve ao fato de que as marés estão relacionadas principalmente a fenômenos astronômicos, que embora complexos, são bastante conhecidos e previsíveis.

O principal fenômeno relacionado com a origem das marés é a força gravitacional exercida pela Lua e pelo Sol sobre a Terra. De maneira mais especifica, quando a Lua está em conjunção ou oposição com o Sol, ou seja, durante a Lua Nova ou Lua Cheia, ocorrem as marés de grandes amplitudes-marés de sizígia. Por outro lado, quando a Lua está em quadrante, ou seja, durante a Lua Quarto Crescente ou Quarto Minguante, ocorrem as marés de menores amplitudes-marés de quadratura. Na Figura 2 são demonstrados mais claramente estes fenômenos.

Sabe-se que os fenômenos astronômicos relacionados com a Terra, Sol e Lua são bastante irregulares, portanto, vários outros fenômenos devem ser levados em consideração. Um exemplo disso são os Equinócios, que ocorrem nos meses de Março e Setembro, que, quando combinados a uma Lua Cheia ou Lua Nova, resultam em marés bem maiores do que as de Sizígia comuns, chamadas de Marés Equinociais.

Na Figura 3 é apresentada a variação dos níveis de marés durante o mês de Setembro de 2010 no porto de Itaquí, na cidade de São Luís-Brasil.

Embora os aspectos astronômicos sejam amplamente conhecidos e previsíveis, nem sempre é possível prever com exatidão o comportamento das marés em longo prazo. Isto se deve ao fato de que as marés podem ser afetadas significativamente pelas 


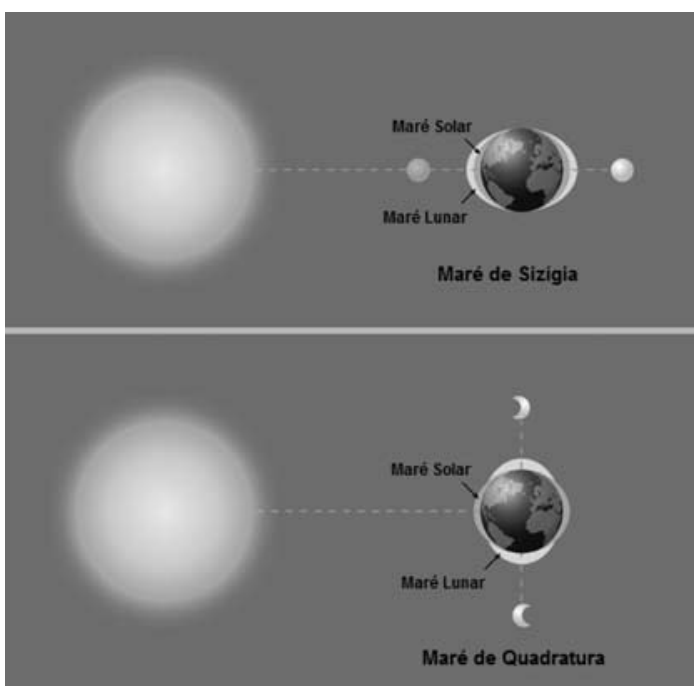

Figura 2. Representação dos fenômenos astronômicos que dão origem às marés de Sizígia e de Quadratura [5].

condições meteorológicas no local: aumento da pressão atmosférica ou ventos soprando da terra para o mar podem reduzir os níveis de marés, por exemplo [5]. Além dos aspectos meteorológicos, as características geomorfológicas da costa também representam um papel importante na modelagem das marés.

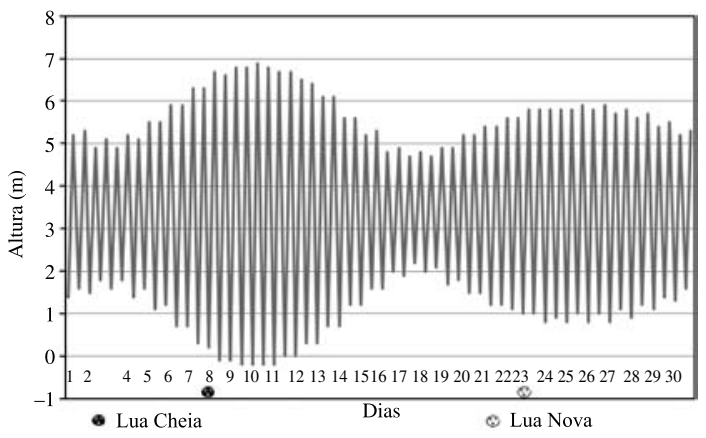

Figura 3. Variação dos níveis de marés durante o mês de Setembro de 2010 no porto de Itaquí, em São Luís-Brasil [6].

Em mar aberto a amplitude máxima das marés não chega a $1 \mathrm{~m}$. À medida que se aproxima da costa, a amplitude das marés é incrementada devido a efeitos de afunilamento, reflexão e ressonância causados pela geometria da costa. $\mathrm{Na}$ Figura 4 é apresentado como estes efeitos afetam significativamente a amplitude da maré no estuário de Severn, no Reino Unido.

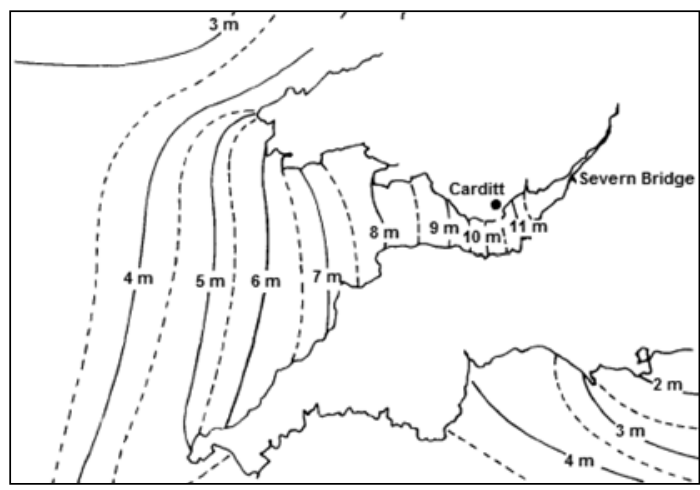

Figura 4. Variação da amplitude de maré ao longo do estuário de Severn, Reino Unido [2].

Portanto, diante de tantos fatores a serem considerados, é comum que a modelagem matemática das marés seja feita através de análise harmônica, ou seja, cada aspecto físico é modelado como uma componente harmônica da maré. Na eq. 1 é apresentado um modelo temporal que melhor se adéqua a esta modelagem [5].

$h(t)=A_{0}+\sum_{i}^{n} f_{i} H_{i} \cos \left[w_{i} t+\left(v_{0}+u\right)_{i}-g_{i}\right]$

Onde:

$h(t)$ : altura da maré em metros no instante $t$;

$H_{i}$ : amplitude em metros da componente $i$;

$w_{i}$ : velocidade angular da componente $i$;

$g$ : $\quad$ fase em graus da componente $i$;

$A_{0}$ : nível médio da maré em metros.

$V_{0}+u$ : argumento na maré de equilíbrio no instante inicial da série;

Estas componentes harmônicas englobam, por exemplo, a translação da Lua em volta da Terra, a precessão do perigeu da Lua, a precessão do periélio do Sol e a precessão do plano orbital da Lua. Existem centros de previsões de marés que utilizam até 62 componentes harmônicas para uma modelagem bastante precisa das marés [5].

\section{MODOS DE APROVEITAMENTO DA ENERGIA MAREMOTRIZ}

Uma das principais formas de exploração da energia das marés é através do uso de turbinas instaladas em barragens. Desta forma, as marés criam um desnível suficientemente elevado entre os lados da barragem, de modo que as turbinas sejam acionadas. Em outras 
palavras: trata-se basicamente do mesmo princípio utilizado em usinas hidroelétricas convencionais. $\mathrm{O}$ principal exemplo de aplicação desta tecnologia é a usina maremotriz de La Rance, na França, ilustrada na Figura 5.

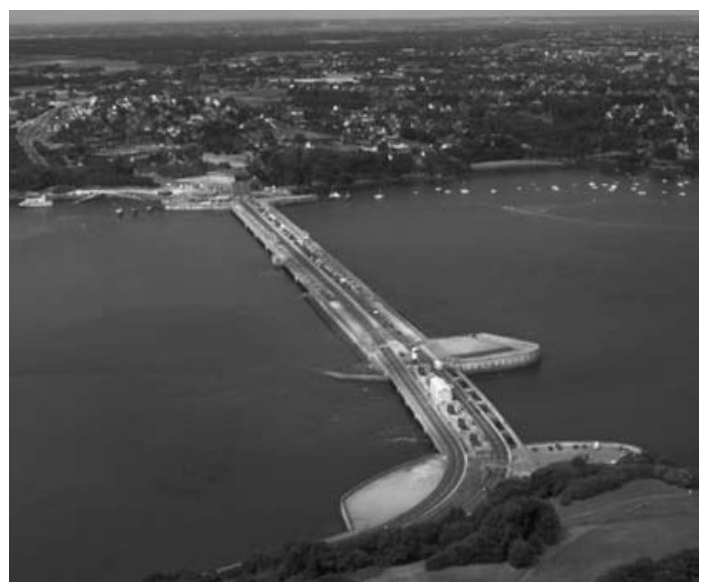

Figura 5. Usina maremotriz de La Rance, na França [7].

Além da necessidade de marés de grandes amplitudes, esta forma de aproveitamento exige ainda que a morfologia do local também seja adequada, ou seja, é necessário que haja condições geográficas favoráveis para o represamento da água, criandose um reservatório. Regiões de estuários, como na costa norte do Brasil, são bons exemplos de locais adequados sob este aspecto.

\section{Modos de Operação de uma Usina Maremotriz}

Existem duas formas principais de aproveitamento da energia potencial das marés: geração em maré vazante e geração em maré enchente. Além disso, é possível a combinação de ambas as formas. Quando o processo de geração ocorre apenas durante a maré vazante ou na maré enchente, é chamada de geração em efeito simples; quando ambas as formas são utilizadas, é chamada de geração em efeito duplo.

A geração em maré vazante é a mais simples estratégia de operação de uma usina maremotriz. Logo após a maré cheia, as comportas de enchimento do reservatório são fechadas. O processo de geração de energia é iniciado durante a maré vazante, quando a queda d'água é aproximadamente a metade da amplitude da maré, ou seja, há queda d'água suficiente para o início do funcionamento das turbinas. Esta operação é mantida até que a altura da queda d'água se torne a mínima possível para a geração de energia. Neste ponto, bloqueiamse as passagens de água através das turbinas, cessando-se a geração de energia até que a altura da queda d'água torne-se novamente suficiente para o funcionamento das turbinas, isto após a maré alta seguinte. Na Figura 6 é ilustrado este processo de operação.

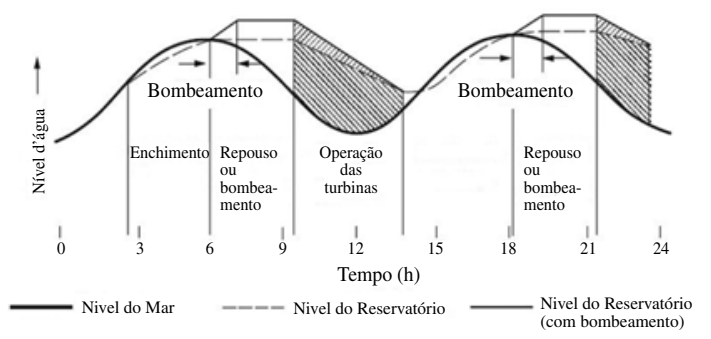

Figura 6. Representação da geração em maré vazante em uma usina maremotriz [1].

O processo de geração em maré enchente é análogo ao ilustrado na Figura 6, com a diferença de que nesse caso o processo de geração ocorre no sentido mar-reservatório. Na Figura 7 é demonstrada a combinação de ambas as formas de aproveitamento, ou seja, geração em efeito duplo.

Os períodos de bombeamento demonstrados nas Figuras 6 e 7 são uma estratégia utilizada para elevar a produção da usina maremotriz através do incremento da altura da queda d'água. Além disso, esta técnica torna-se bastante útil para aumentar a flexibilidade da operação da usina.

\section{ASPECTOS AMBIENTAIS}

Embora a exploração da energia maremotriz não produza nenhuma poluição direta ao meio-ambiente, é importante ressaltar que os efeitos da construção e operação de uma usina maremotriz em um estuário devem ser cuidadosamente avaliados, pois a sua instalação pode modificar algumas características naturais do local. Além disso, as possíveis alterações nas atividades humanas locais também devem ser avaliadas.

A construção de uma barragem em um estuário pode resultar em efeitos diretos sobre o ecossistema local. Portanto, é importante ressaltar que tais efeitos devem ser considerados tanto no projeto e construção, quanto na operação da usina. 
Alguns dos aspectos que devem ser analisados são as possíveis alterações na qualidade da água, ou seja, alterações nas características químicas da água, tais como oxigenação e salinização; além da própria morfologia do estuário, que pode ser alterada devido às possíveis modificações nos regimes de sedimentação e erosão.

Possivelmente, um dos principais aspectos ambientais que devem ser verificados está relacionado às alterações no ecossistema do estuário. Estas alterações variam de acordo com o local, entretanto, podem ser formuladas levando-se em consideração os seguintes aspectos [1]:

- Alterações na distribuição das espécies dentro do estuário;

- Alterações na composição do grupo de espécies: algumas podem deixar de existir, enquanto novas espécies podem surgir;

- Alterações nos ciclos de vida de algumas espécies: taxas de crescimento e reprodução, por exemplo.

Embora estes aspectos devam ser cuidadosamente verificados, vale destacar que a intensidade em que estes podem ocorrer, varia de um local para outro. Tomando-se como referência a usina maremotriz de La Rance, observou-se que os impactos mais significativos aconteceram apenas durante a sua construção, onde o fluxo natural do estuário foi interrompido através de ensecadeiras, para a construção a seco da barragem. Após esta etapa, estes impactos foram substancialmente reduzidos. Com relação ao ecossistema do estuário de La Rance, foram observadas algumas modificações ao longo dos anos até que um novo equilíbrio ecológico tenha sido alcançado [8]. Entretanto, estas modificações não causaram prejuízos às atividades pesqueiras na região [3].

Algumas soluções podem ser adotadas no sentido de amenizar os impactos sócio-ambientais causados pela construção e operação de uma usina maremotriz. A exemplo da construção da usina de Kislaya GubaRússia, a utilização de elementos pré-fabricados em terra firme para a construção da barragem torna-se uma solução menos ofensiva ao meio-ambiente do que a utilização de ensecadeiras. Além disso, a exemplo de La Rance, a utilização de eclusas pode conciliar a usina ao tráfego de embarcações através do estuário.

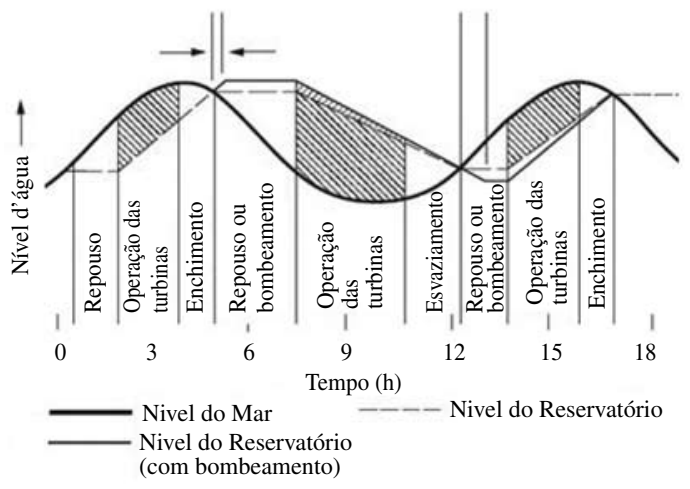

Figura 7. Representação da geração em efeito duplo em uma usina maremotriz [1].

\section{ASPECTOS ECONÔMICOS}

A avaliação econômica de um projeto de usina maremotriz deve ponderar tantos aspectos diretos quanto indiretos. Entre os aspectos diretos estão os custos de construção, operação e manutenção da usina, além dos benefícios promovidos pela própria geração de eletricidade. Os aspectos indiretos estão relacionados aos impactos ambientais e sócio-econômicos associados á usina [1]. O desenvolvimento de atividades turísticas no entorno da usina e a utilização da barragem como via de acesso rodoviário são exemplos de benefícios indiretos.

Além de a fonte primária ser virtualmente inesgotável, os custos associados à operação da usina são mínimos, portanto, os investimentos em construção e operação podem ser facilmente recuperados através de "economia em combustíveis".

Ao contrário de outras fontes energéticas, a geração maremotriz está livre de alguns problemas tais como: emissões de gases poluidores, poluição da água, derramamentos de óleo, produção de resíduos. Embora sejam primordialmente ambientais, estes aspectos também devem ser observados sob o ponto de vista econômico em quaisquer projetos de geração de energia. Além disso, a vida útil de uma usina maremotriz pode chegar de duas a três vezes a de uma térmica ou nuclear [3].

A viabilidade econômica de uma planta maremotriz está bastante atrelada às demais fontes energéticas também disponíveis. A energia maremotriz pode ser bastante competitiva se compara àquela 
proveniente de usinas a carvão, entretanto, esta competitividade é reduzida se compara às hidrelétricas convencionais. Portanto, o custo da geração maremotriz e consequentemente a sua viabilidade, varia de um país para outro, de acordo com as condições energéticas, sociais e ambientais diversas. O Japão, por exemplo, produz eletricidade a baixos custos a partir de fontes nucleares e térmicas a gás e a óleo. Uma usina maremotriz produziria eletricidade a um custo de 3 a 4 vezes maior, o que a tornaria não-atrativa [3].

A construção de uma barragem pode representar um dos maiores custos para a implantação de uma usina maremotriz, portanto, uma maneira eficaz de prever a sua efetividade é a través da razão de Gibrat, apresentada na eq. 2. Portanto, quanto menor a razão de Gibrat, melhor o indicativo de viabilidade do projeto.

$$
\text { Gibrat }_{\text {Ratio }}=\frac{C_{m}}{E_{k W h}}
$$

Onde:

$\mathrm{C}_{\mathrm{m}}$ : Comprimento da barragem, em metros;

$\mathrm{E}_{\mathrm{kWh}}$ :Energia produzida pela usina durante um ano, em kWh.

O desenvolvimento de novas tecnologias, principalmente para aproveitamentos de baixas quedas, tem tornado economicamente atrativos diversos pequenos projetos maremotrizes. Por exemplo, em [9-10] são apresentadas algumas possibilidades, bem como a viabilidade de aproveitamento em pequena escala, na barragem do Bacanga, no Brasil. Em [11-12] é justificada a viabilidade de inúmeros pequenos aproveitamentos na baía de Turiaçu, também no Brasil.

\section{COMPONENTES DE UMA USINA MAREMOTRIZ}

Os principais componentes de uma usina maremotriz são: barragem, turbogeradores, além de um ou mais reservatórios. Na Figura 8 são esquematizados os principais componentes de uma usina maremotriz.

\section{Barragem}

A construção da barragem representa uns dos fatores mais relevantes em uma usina maremotriz,

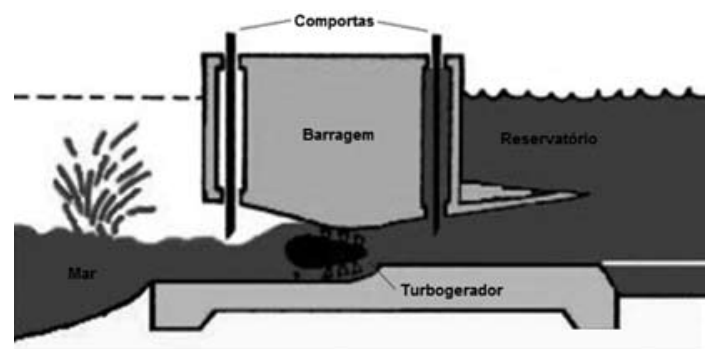

Figura 8. Esquema ilustrativo dos componentes de uma usina maremotriz [13].

principalmente por se relacionar de forma bastante significativa com os custos totais de implantação da usina.

O projeto da barragem em uma usina maremotriz deve prever uma série de condições que são especificas pra este tipo de aproveitamento [1]:

- A barragem deve prever os efeitos das ondas que se chocam contra ela. Estes efeitos podem ser bastantes severos devido à variação constante de pressão entre ambos os lados;

- A localização e o formato da barragem podem alterar os fenômenos de ressonância e reflexão que ocorrem dentro de um estuário. Desta forma, é possível elevar ou atenuar a amplitude da maré $\mathrm{e}$, consequentemente, a energia produzida pela usina. Portanto, este é um fator que deve ser analisado cuidadosamente.

\section{Comportas}

As comportas incorporadas à barragem de uma usina maremotriz tem a função principal de controlar o nível de água do reservatório, sendo que a frequência em que estas são abertas está relacionada ao tipo de maré e ao modo de operação da usina.

As comportas usadas em uma usina maremotriz operam com muito mais frequência do que em uma hidrelétrica convencional. Portanto, é necessário que estas operem com maior rapidez e com elevado grau de confiabilidade, de modo a evitar problemas operacionais e manutenções constantes.

Outro importante fator que deve ser considerado é o ambiente de operação das comportas. Os constantes impactos das ondas e a corrosão podem resultar em problemas operacionais às comportas e, portanto, devem ser levados em consideração. 


\section{Reservatório}

A principal função do reservatório em uma usina maremotriz é o armazenamento de água, de modo a gerar a queda d'água necessária para geração de eletricidade através dos turbogeradores. Estes reservatórios podem ser reentrâncias costeiras, enseadas, corpos de águas entre ilhas e continentes, ou estuários. [14].

O projeto de uma usina maremotriz pode envolver um ou mais reservatórios, sendo que a primeira alternativa é a mais comum e mais econômica, embora tenha menos flexibilidade. Um dos principais projetos maremotrizes em que há propostas de se utilizar múltiplos reservatórios (ou múltiplos lagos) é no estuário de Severn, no Reino Unido [15]. Na Figura 9 é apresentada uma destas propostas.

\section{Equipamentos Eletromecânicos}

Os equipamentos destinados à conversão de energia são uma das principais parcelas que compõem o custo total de uma usina maremotriz, podendo ser responsáveis por cerca de 45 a 55\% destes custos [1].

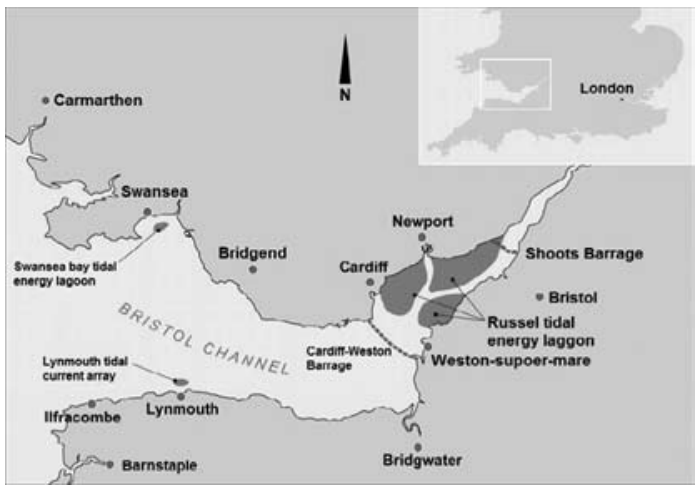

Figura 9. Representação de uma das propostas de utilização de múltiplos lagos no estuário de Severn, Reino Unido [15].

Em uma usina maremotriz, os equipamentos eletromecânicos devem levar em consideração os seguintes fatores [1]:

- A variação contínua da altura da queda d'água requer turbinas que operem de forma relativamente eficiente sob tais condições;

- A baixa queda requer um grande volume de água passando pelas turbinas resultando em grandes dimensões físicas para as passagens da água;
- A operação cíclica (início e parada da geração de acordo com as marés) impõe nos equipamentos geradores, fadigas maiores do que na geração convencional em hidrelétricas;

- As dimensões físicas de cada unidade geradora deve ser a menor possível, visto que afetam diretamente os custos das obras civis;

- Os materiais são expostos às ações corrosivas da água do mar e, portanto, precisam ser cuidadosamente selecionados e protegidos;

- A eficiência global da geração pode assumir uma prioridade menor devido à ampla fonte de água envolvida no processo.

Os principais modelos de turbinas utilizadas para conversão da energia maremotriz são as do tipo Kaplan, STRAFLO e as do tipo Bulbo. Nas Figuras 10 e 11 são ilustradas a turbina STRAFLO, empregada na usina maremotriz de Annapolis Royal, no Canadá e a do tipo bulbo, utilizada na usina maremotriz de La Rance, respectivamente.

Uma enorme parcela do potencial energético maremotriz global ainda se encontra inexplorado, por se tratar de locais com amplitudes de maré relativamente menores. $\mathrm{O}$ aproveitamento de lugares de queda muito baixa é geralmente possível tecnicamente, porém não é viável economicamente devido aos custos de obras civis associados a uma produção energética em menor escala.

Entretanto, novas tecnologias em equipamentos eletromecânicos têm promovido uma redução significativa nos custos de obras civis, de modo a permitir a exploração de locais com queda muito baixa. Dentre estas novas tecnologias estão os modelos VLH (Very Low Head) e a HYDROMATRIX ${ }^{\circledR}$.

O modelo $V L H$, ilustrado na Figura 12, foi projetado para aplicações de quedas entre 1,4 e 3,2 m. O modelo possui uma turbina Kaplan e pode produzir uma potência entre 100 kW e 500 kW [16].

O sistema HYDROMATRIX ${ }^{\circledR}$ é composto de pequenas unidades geradoras dispostas em uma "matriz", conforme ilustrado na Figura 13, sendo facilmente integrado a uma barragem já existente, e projetada para quedas entre 3 a $30 \mathrm{~m}$. A potência gerada por cada unidade vai de $200 \mathrm{~kW}$ té $700 \mathrm{~kW}$ [17]. 


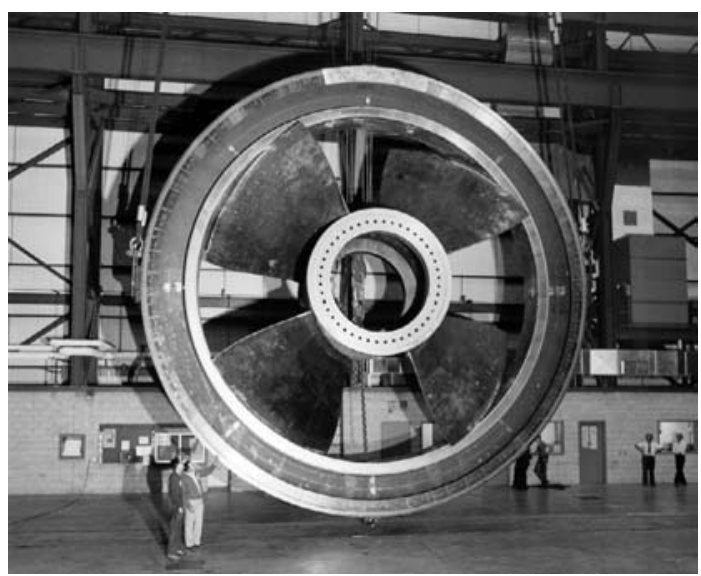

Figura 10. Detalhes da turbina STRAFLO antes de sua instalação na usina maremotriz de Annapolis Royal, Canadá [17].

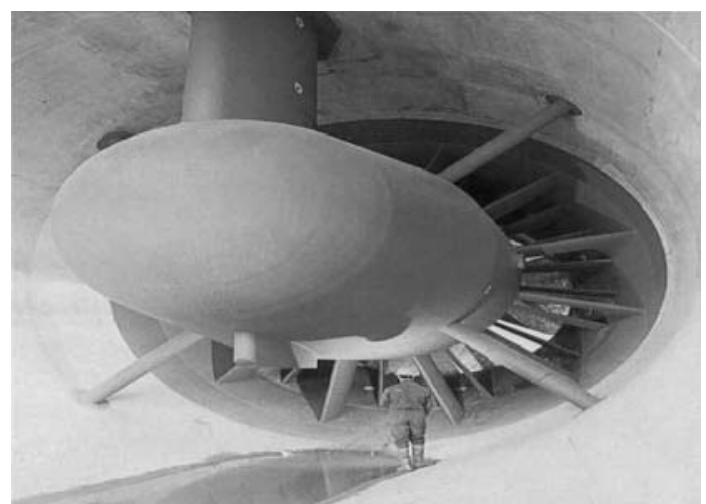

Figura 11. Detalhes da turbina bulbo instalada na usina maremotriz de La Rance, França [7].

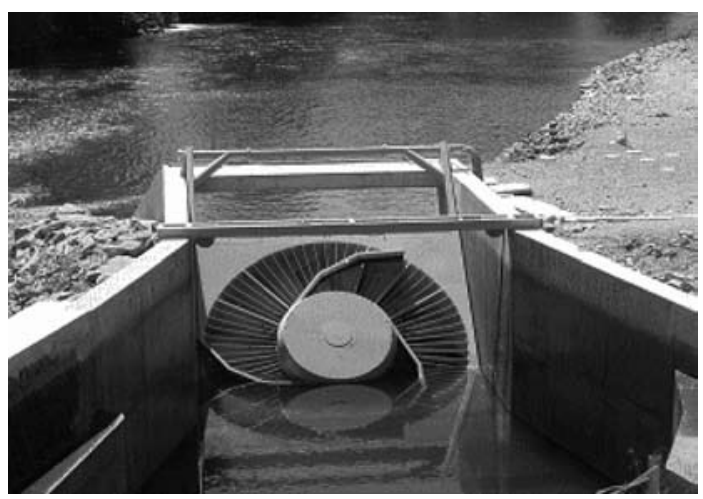

Figura 12. Vista do modelo VLH após a sua instalação em Milau, França [16].

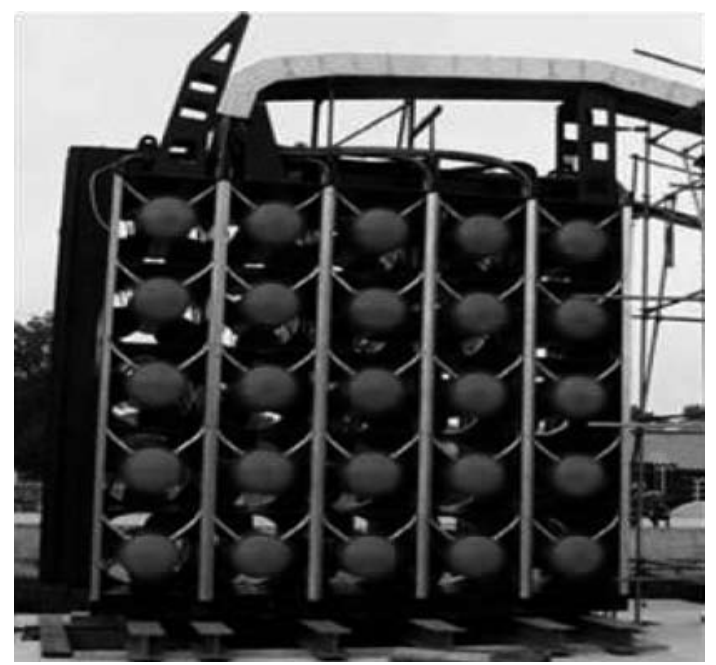

Figura 13. Detalhes do sistema HYDROMATRIX ${ }^{\circledR}$ antes de sua instalação em Freudenau, Áustria [17].

\section{USINAS MAREMOTRIZES EXISTENTES}

Embora o potencial energético global das marés seja enorme, apenas alguns poucos projetos de usinas maremotrizes se tornaram realidade até o momento. Algumas das principais referências em termos de projetos já implementados são a França (La Rance), Canadá (Annapolis Royal) e Rússia (Kislaya Guba), além de inúmeros pequenos projetos de pequeno porte em operação na China.

\section{Usina Maremotriz de La Rance}

A usina maremotriz de La Rance-Figura 5-é atualmente a maior do mundo em potência instalada-240 MW. A estratégia de operação da usina é uma combinação de efeito duplo e bombeamento. A produção anual da usina pode chegar a $544 \mathrm{GWh}$, sendo que $10 \%$ deste total é usado para fins de bombeamento [3].

A usina é composta de 24 grupos-geradores do tipo bulbo, cada um com potência nominal de 10 MW. As turbinas possuem sistema de reversão das hélices para permitir a geração em ambos os sentidos, além do bombeamento, que é feito pelo mesmo grupo de máquinas. No estuário de La Rance, as marés podem alcançar até $14 \mathrm{~m}$, portanto, o bombeamento geralmente é utilizado em marés abaixo de $9 \mathrm{~m}$.

Além da geração de eletricidade, outros benefícios provenientes da construção da usina foram 
observados: a usina tornou-se um atrativo turístico na região; a indústria pesqueira não sofreu qualquer dano durante os anos de operação da usina; surgimento de novas comunidades planejadas próximas à usina (Gougeonnais) [3].

\section{Usina Maremotriz de Annapolis Royal}

A usina maremotriz de Annapolis Royal foi construída na década de 80 utilizando-se uma barragem já existente no rio Annapolis. Ao contrário de La Rance e Kislaya Guba, o modelo de turbina utilizado é STRAFLO e não bulbo. A potência instalada da usina é de 17, $8 \mathrm{MW}$ [1].

Devido a questões ambientais, o nível do reservatório deve ser mantido a níveis abaixo do que foi inicialmente planejado. Desta forma, a produção anual da usina é menor do que os $50 \mathrm{GWh}$ estimados inicialmente. Apesar desta restrição operacional, a usina é despachada comercialmente e sendo, portanto, considerada um projeto bem sucedido [1].

\section{Usina Maremotriz de Kislaya Guba}

A usina maremotriz de Kislaya Guba é considerada um caso especial de exploração da energia maremotriz. Construída na década de 60 no mar de Barents, a usina possui $400 \mathrm{~kW}$ de potência instalada e foi idealizada para fins experimentais apenas: condições climáticas bastante severas e pequenas amplitudes de marés (1,3 a 3,9 m) tornaram a usina inviável para fins comerciais. Além disso, a usina permaneceu quase uma década fora de operação. Isto fez com que as características ambientais do estuário fossem profundamente alteradas durante aquele período.

\section{NOVOS PROJETOS E PRINCIPAIS TENDÊNCIAS}

Embora existam relativamente poucos projetos de usinas maremotrizes implementados em todo o mundo, diversos países tem se despertado para a possibilidade de exploração desta fonte energética em seus litorais.

Alguns países tais como Egito [18], Índia [19], Rússia [20], Malásia [21], Colômbia [22], Austrália [23], Reino Unido [15, 24-25] e Brasil [9-12] já apresentam estudos e propostas sobre as possibilidades de exploração da energia maremotriz em seus mares.
Um caso bastante especial é o estuário de Severn, no Reino Unido. Trata-se de um dos principais projetos atualmente em andamento devido à possibilidade de utilização de múltiplos lagos dentro do estuárioFigura 6.

Até o momento, este trabalho abordou especificamente a exploração da energia maremotriz através de represamentos em reservatórios. Entretanto, vale destacar a existência de outras formas de exploração da energia dos mares, que podem ser através das correntes de marés, ondas, gradiente térmico e gradiente de salinidade.

As correntes de marés podem ser convertidas em eletricidade através de sistemas modulares de turbinas que podem ser colocadas diretamente no leito do mar, conforme exemplificado na Figura 14.

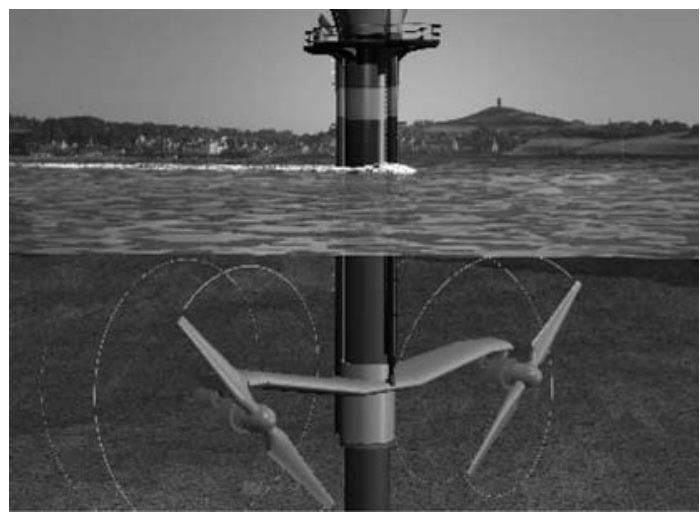

Figura 14. Ilustração de uma turbina utilizada para conversão da energia cinética das correntes de maré em eletricidade [26].

Uma das desvantagens do aproveitamento das correntes de marés está na limitação da energia disponível, pois neste caso as marés apresentam uma baixa densidade energética. Entretanto, os custos reduzidos de instalação e os impactos ambientais mínimos tem tornado essa opção tecnológica bastante atrativa em vários aspectos.

Apesar de a exploração comercial das correntes de marés está em desvantagem com relação à exploração através de barragens [27], esta alternativa tecnológica também apresenta uma tendência bastante promissora e tem sido bastante pesquisada e também levada em consideração para novos possíveis projetos [28-31]. 
Embora esta forma de aproveitamento apresente os mesmo princípios da geração eólica. Algumas vantagens são notavelmente observadas: a densidade da água do mar é cerca de 800 vezes maior do que a do ar, além disso, as correntes de marés são altamente previsíveis-até $98 \%$ de certeza para um período de décadas, ao contrário dos ventos [28].

O potencial extraível a partir das correntes de marés pode ser obtido a partir da eq. 3 .

$$
P=\frac{1}{2} \rho A v^{3}
$$

Onde:

$P$ : potencial extraível, em $\mathrm{W}$;

$\rho$ : densidade da água do mar, em $\mathrm{kg} / \mathrm{m}^{3}$;

$A$ : área da seção transversal da turbina, em $\mathrm{m}^{2}$;

$v$ : velocidade da corrente de maré, em $\mathrm{m} / \mathrm{s}$.

As principais tecnologias empregadas nesta forma de aproveitamento são baseadas em turbinas de eixo vertical, e de eixo horizontal.

O Projeto SeaGen é um dos principais exemplos de aproveitamentos da correntes de marés. Em 2008, um conversor de 1,2MW-Figura 14 -foi instalado em Stranford Lough, Reino Unido. O diâmetro do rotor é de $16 \mathrm{~m}$, sendo capaz de gerar anualmente cerca de $3800 \mathrm{MWh}$. A velocidade nominal é de apenas $2,4 \mathrm{~m} / \mathrm{s}$ [32].

Outro projeto em andamento, engloba o aproveitamento das correntes de marés nas proximidades da ilha de Anlesey, País de Gales. Este projeto consiste na criação de um array composto por sete turbinas SeaGen, totalizando $10,5 \mathrm{MW}$ de potência instalada. Desta forma, pretende-se avaliar os diversos aspectos relacionados à utilização desta tecnologia para geração de energia. Além disso, espera-se que este projeto promova alguns benefícios indiretos, tais como incentivo às atividades turísticas na região [33].

A companhia Hammerfest Strom desenvolveu o projeto chamado Blue Concept, ilustrado na Figura 15, que consiste em um protótipo pré-comercial de turbinas de até $1 \mathrm{MW}$ de potência nominal para o aproveitamento das correntes de marés. Com o objetivo de reduzir os custos da geração maremotriz, a companhia pretende testar seus protótipos em Islay e Ducany, Escócia, através de arrays com potências nominais de 10MW e 95MW, respectivamente [34].

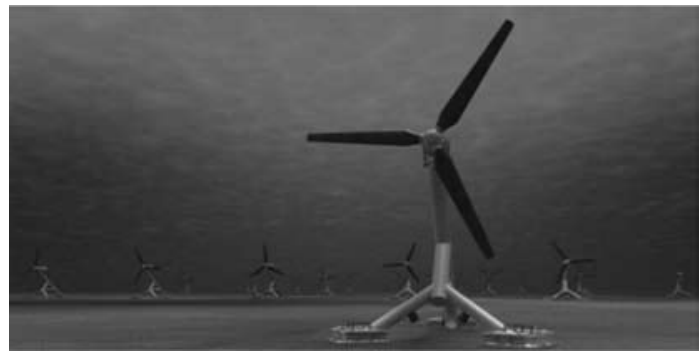

Figura 15. Ilustração do Blue Concept, desenvolvido pela Hammerfest Strom [34].

Recentemente, alguns estudos tem proposto a integração entre geração maremotriz e geradores eólicos off-shore. Modelos de tais sistemas híbridos tem sido implementados e simulados de modo a se prever a interação dinâmica entre ambas a fontes, bem como o sistema elétrico em que estão conectadas [35-37].

\section{ENERGIA MAREMOTRIZ NO BRASIL: ESTUDO DE CASOS}

No Brasil, as maiores amplitudes de marés se encontram na costa norte. Estudos realizados ainda na década de 80 revelaram alguns locais potencialmente favoráveis à exploração da energia maremotriz. Por exemplo, apenas no litoral do estado do Maranhão, estimou-se um potencial disponível acima de $8 \mathrm{GW}$ [38].

\section{Estuário da Bacanga}

Situado na cidade de São Luís, o estuário do Bacanga, ilustrado na Figura 16, representa um caso bastante interessante para exploração da energia das marés. Ainda na década de 70 foi construída uma barragem no estuário visando a interligação da cidade com o porto de Itaquí. Além disso, na época da construção da barragem já se pensava em aproveitá-la para geração de eletricidade.

$\mathrm{Na}$ época de construção da barragem, diversos estudos foram realizados sobre as possibilidades de aproveitamento desta para geração de eletricidade. Uma das alternativas consistia na utilização de 6 turbogeradores do tipo bulbo de $4500 \mathrm{~kW}$ cada, operando em regime de efeito simples. Desta forma, a geração anual da usina seria estimada em 56,3 GWh [9]. 
Embora fosse um projeto bastante promissor, a sua implantação tornou-se inviável economicamente devido a uma série de fatores posteriores: ocupação urbana desordenada em áreas do reservatório e a criação de uma avenida que também margeia o reservatório obrigaram que este fosse mantido, através do controle das comportas da barragem, a uma cota máxima bem inferior ao previsto no projeto inicial.

Atualmente, entretanto, existem propostas da criação de uma usina-piloto para fins de pesquisa apenas, tendo em vista que este conhecimento possa ser revertido para outras regiões do Brasil que possuam potencial mais significativo.

Em [9] são apresentados detalhadamente os motivos que inviabilizaram o projeto inicial da usina, além de apresentar como proposta uma usina-piloto, bem como as principais justificativas que viabilizam esta nova concepção. Em [10] é apresentado um estudo bastante detalhado sobre a morfologia do estuário, bem como uma proposta tecnicamente viável de utilização da barragem e comportas já existentes, seguindo também a concepção de uma usina-piloto no estuário do Bacanga.

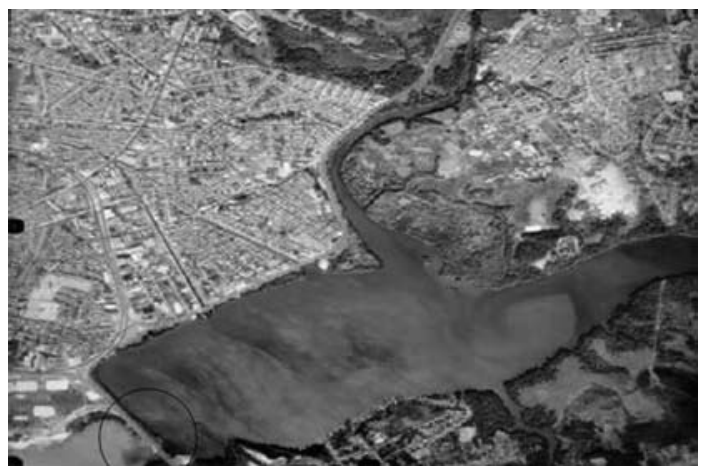

Figura 16. Vista aérea do estuário e da barragem do Bacanga [39].

Entre os principais motivos que justificam a implantação da usina-piloto maremotriz do Bacanga, destaca-se a oportunidade de impulsionar o desenvolvimento tecnológico e humano visando-se outros projetos maremotrizes no Brasil. Na figura 17 é ilustrado um modelo de usina proposto em [10] para a barragem do Bacanga.

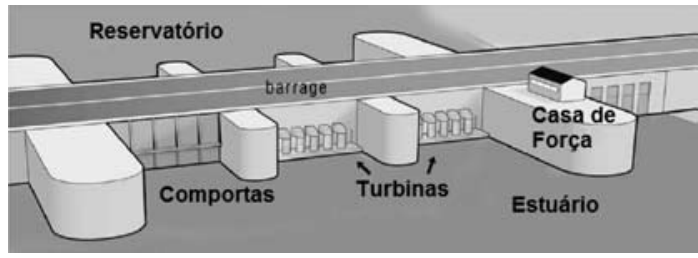

Figura 17. Ilustração do layout proposto para a usina maremotriz do Bacanga, Brasil [10].

\section{Baía de Turiaçu}

Localizada no estado do Maranhão, Brasil, a baía de Turiaçu apresenta um dos maiores potenciais maremotrizes do litoral brasileiro: mais de 3,4 GW de potencial disponível [38].

A baía de Turiaçu é uma região riquíssima em estuários, além de apresentar marés de até $7 \mathrm{~m}$, portanto, é considerada uma região bastante propícia para este tipo de exploração energética. Entretanto, existe uma série de restrições que tornam inviáveis a exploração em larga escala de todo este potencial, tais como: dificuldades de acesso ao local e restrições ambientais relacionadas com a abundante vegetação de mangues na região.

Em [11] são apresentados detalhadamente os principais motivos que inviabilizam projetos em larga escala na região, além de propor, como alternativa, a exploração de pequenos estuários através de tecnologias já disponíveis no mercado para aproveitamentos de baixas quedas. De maneira complementar, em [12] é apresentada uma análise de vários possíveis cenários de geração em um pequeno estuário dentro da baía de Turiaçu, ou seja, são feitas análises considerando diferentes quantidades de turbinas de modo que haja o melhor compromisso entre energia produzida e respeito às restrições ambientais do local.

Portanto, no contexto de projetos em pequena escala, a baía de Turiaçu apresenta um horizonte bastante amplo para o aproveitamento da energia maremotriz através da exploração de inúmeros pequenos estuários [11-12].

\section{CONCLUSÃO}

Os grandes desafios do setor energético mundial colocam as fontes alternativas em posição de destaque, tendo em vista que a maior participação 
destas na matriz energética mundial será uma tendência inevitável nos próximos anos, portanto, os estudos sobre a exploração da energia maremotriz tornam-se de bastante interesse sob o ponto de vista estratégico.

Embora em todo o mundo exista um número relativamente pequeno de usinas maremotrizes em pleno funcionamento, a tecnologia já utilizada neste tipo de geração, bem como os princípios operacionais adotados, já se mostrou bastante madura e confiável e, portanto, pode ser reproduzida seguramente em diversos outros locais com potencial significativo para este modelo de geração de eletricidade.

Vale destacar que os métodos convencionais de exploração da energia maremotriz através de barragens necessitam de estudos bastante detalhados que englobem os impactos ambientais e sociais na região. Pois, embora seja uma fonte livre de emissões, ainda assim os seus impactos ambientais podem ser significativos.

Com relação aos impactos sócio-econômicos, projetos existentes, como a usina de La Rance, demonstram não só a plena capacidade de se adequar a operação de uma usina maremotriz convencional às atividades humanas locais, mas também a oportunidade de alavancar atividades econômicas principalmente através do turismo.

Um dos principais fatores que tem impulsionado a exploração maremotriz são os avanços alcançados por parte dos equipamentos eletromecânicos usados na conversão da energia das marés. Esta situação permite a exploração até mesmo em situações de baixa queda, o que constitui um ponto bastante favorável para esta forma de geração de energia.

Outro aspecto a ser destacado é surgimento de novas formas de exploração da energia das marés que tem sido pesquisadas e avaliadas de maneira bastante intensa e demonstram ser bastante promissoras, sendo que a principal delas é o aproveitamento das correntes de marés, que devido à sua simplicidade conceitual, apresenta impactos ambientais mínimos e baixo custo de instalação e operação, o que implica em incentivos à sua utilização em grande escala.

Portanto, a maturidade da tecnologia já usada em usinas maremotrizes, o surgimento de novas tecnologias e formas de aproveitamentos, bem como a existência de inúmeros locais adequados e ainda inexplorados, leva a concluir que a exploração maremotriz atende aos principais requisitos para que esta possa ser utilizada mais intensamente e represente uma parcela mais significativa na matriz energética mundial.

\section{AGRADECIMENTOS}

Os autores agradecem ao CNPq (Projeto 555797/20104 Pesquisa e Desenvolvimento para a Implantação de uma Usina-Laboratório Maremotriz na Barragem do Bacanga) e ao MME/PNUD pelo apoio na realização deste trabalho.

\section{REFERÊNCIAS}

[1] R.H. Clark. "Elements of Tidal-Electric Engineering". Wiley-IEEE Press, p. 280. 2007.

[2] Th.J. Hammons. "Tidal Power". Proceedings of the IEEE. Vol. 8, Issue 3, pp. 419-433. March, 1993.

[3] R.H. Charlier and C.W. Finkl. "Ocean Energy. Tide and Tidal Power". First Edition. Springer, p. 262.2009.

[4] Atlantis Resources Corporation. "Marine Power-Global Resource". 2010. Date of visit: 05 de Novembro de 2010. URL: www.atlantisresourcescorporation.com

[5] Instituto Hidrográfico. "Marés-Marés Vivas, Marés Mortas e Marés Vivas Equinociais". 2010. Date of visit: 06 de Novembro de 2010. URL: www.hidrografico.pt

[6] Diretoria de Hidrografia e Navegação. Centro de Hidrografia da Marinha. Banco Nacional de Dados Oceanográficos. "Previsões de Marés-Porto de Itaquí, São Luís". 2009. Date of visit: 06 de Novembro de 2010.

URL: www.mar.mil.br

[7] Faites le Plein d'Avenir-Le Blog des Energies Renouvelables. "L'usine Marémotrice de La Rance-La Première Usine Marémotrice Du Monde". 2008. Date of visit: 19 de abril de 2001. URL: www.faiteslepleindavenir.com

[8] J. Pierre Frau. "Tidal Energy: Promissing Projects-La Rance: a succesful industrial-scale experiment". IEEE Transactions on Energy Conversion. Vol. 8, Issue 3, pp. 552-558. September, 1993. 
[9] Sh.L. Lima, O.R. Saavedra, A.K. Barros e N.J. Camelo. "Projeto da Usina Maremotriz do Bacanga: Concepção e Perspectivas". $5^{\text {th }}$ Latin-American Congress Electriciy Generation and Transmission. UNESP. Vol. 1, pp. 1-6. 2003.

[10] R.M. Ferreira and S.F. Estefen. "Alternative Concept for Tidal Power Plant with Reservoir Restrictions". Renewable Energy. Vol. 34, Issue 4. pp. 1151-1157. 2009.

[11] L. Neto, P.B., Oliveira, D.Q., N.J. Camelo e O.R. Saavedra. "Estudo do Potencial para Geração de Energia Elétrica a partir de Fonte Maremotriz". The $8^{\text {th }}$ Latin-American Congress on Electricity Generation and TransmissionCLAGTEE. Anais do CLAGTEE 2009. Vol. 1, pp. 709-713. 2009.

[12] L. Neto, P.B., O.R. Saavedra, N.J. Camelo e L.S.A. Ribeiro. "Viabilidade de Pequenos Aproveitamentos para Geração de Energia Eletromaremotriz". XVIII Congresso Brasileiro de Automática. Anais do CBA 2010. Vol. 1, pp. 66286-66292. 2010.

[13] Sh. Massoud, M. Amer and M. Samir. "Tidal Power Generation Systems". 2001.

[14] R.H. Charlier. "Tidal Energy". Van Nostrand Reinhold Company. Vol. 1, p. 351. New York, NY, USA. 1982.

[15] Sustainable Development Commision. "Tidal Power in United Kingdon-Research Report 4-Severn non-barrage Options". EAE Energy \& Enviroment. October 2007.

[16] MJ2 Technologies. “The VLH Range". 2010. Date of visit: November 09, 2010.

URL: www.vlh-turbine.com

[17] Andritz. "Hydromatrix-Main Conditions and Application Criteria". 2010. Date of visit: November 09, 2010.

URL: www.andritz.com

[18] F.H. Fahmy. "An Optimum Operation and Mathematical Model of Tidal Energy System at Red Sea Area". Chemistry and Chemical Engineering International Conference. Vol. 1, pp. 664-667. 2010.

[19] Chittora Madhu. "India's First Tidal Power Project Coming up". Project Monitor. 2010. Date of visit: November 09, 2010.

URL: www.projectsmonitor.com

[20] L.B. Bernshtein. "Tidal Power Development-A Realistic, Justifiable and Topical Problem of Today". IEEE Transactions on Energy
Conversion. Vol. 10, Issue 3, pp. 591-599. 1995.

[21] L.K. Siong and L.Y. Seng. "Preliminary Investigation of the Potential of Harnessing Tidal Energy for Electricity Generation Malaysia”. Transmission and Distribution Conference and Exposition. Vol. 1, pp. 1-7. April 21-24, 2008.

[22] J.M. Pólo, J. Rodríguez y A. Sarmiento. "Potencial de Generación de Energía a lo Largo de la Costa Colombiana Mediante el Uso de Corrientes Inducidas por Mareas". Revista de Ingeniería-Universidad de los Andes. Ed. 28, pp. 99-105. 2009.

[23] Hydro Tasmania Hydro Electric Corporation. "Study of Tidal Energy Technologies for Derby". Sustainable Energy Development Office-Government of Western Australia. Report N ${ }^{\circ}$ WA-107384-CR-01. 2001.

[24] J. Radtke, S. J. Couch and C. J. Dent. "Capacity of Large Tidal Barrages". IEEE $11^{\text {th }}$ International Conference on Probabilistic Methods Applied to Power Systems. Vol. 1. pp. 331-336. 2010.

[25] Sustainable Development Commission. "Turning the Tide-Tidal Power in the UK". Sustainable Development Commission. 2010. Date of visit: 09 de novembro de 2010. URL: http://www.sd-commission.org.uk/

[26] Marine Current Turbines. "Strangford Lough Marine Current Turbine-Environmental Statement (Non-Technical Summary)”. 2005. Date of visit: 15 de abril de 2011. URL: http://www.seageneration.co.uk/

[27] Jahangir Khan and Gouri S. Bhuyan. "Ocean Energy: Global Technology Development Status". IEA-OES. Document No. T0104. 2009. Date of visit: 9 de novembro de 2010. URL: www.iea-oceans.org

[28] S.E. Ben Elghali, M.E.H. Benbouzid and J.F. Charpatier. "Marine Tidal Current Electric Power Generation Technology: State of the Art and Current Status". IEEE International Electric Machines \& Drives Conference. Vol. 1, pp. 1407-1412. 2007.

[29] S. Gooch, J. Thomson, B. Polagye and D. Meggitt. "Site Characterization for Tidal Power". Marine Technology for Our Future: Global and Local Challenges. OCEANS, MTS/IEEE Biloxi, pp. 1-10. 2009. 
[30] J. King and T. Tryfonas. "Tidal Stream Power Technology-State of the Art". Oceans 2009Europe, pp. 1-8. 2009.

[31] N.E. Turner and A. Ower. "The Development of a Tidal Turbine for Deployment in Areas with Slow Moving Tidal Flows". Oceans 2007-Europe. pp. 1-3. 2007.

[32] Marine Current Turbines. "SeaGen Fact Sheet". 2011. Date of visit: 15 de abril de 2001. URL: www.seageneration.co.uk

[33] Marine Current Turbines. "Skerries Tidal Stream Array". 2011. Date of visit: 15 de abril de 2001. URL: www.seagenwales.co.uk

[34] Hammerfest Strom. "Blue Concept". 2011. Date of visit: 15 de abril de 2011. URL: www.hammerfeststrom.com

[35] M. Lutfur Rahman and Y. Shirai. "Hybrid Offshore-wind and Tidal Turbine (HOTT) Energy Conversio I (6-Pulse GTO Rectifier and Inverter)". IEEE Conference on Sustainable Energy Technologies. Vol. 1, pp.650-655. 2008.
[36] T. Aboul-Seoud and A.M. Sharaf. "A Dynamic Voltage Regulator Compensation Scheme for a Grid Connected Village Electricity Hybrid Wind/Tidal Energy Conversion Scheme". IEEE Electrical Power \& Energy Conference. Vol. 1, pp. 1-6. 2009.

[37] M. Lutfur Rahman, Sh. Oka and Y. Shirai. "Hybrid Power Generation System Using Offshore-Wind Turbine and Tidal Turbine for Power Fluctuation Compensation (HOT-PC)". IEEE Transactions on Sustainable Energy. Vol. 1, Issue 2. 2010.

[38] Centrais Elétricas Brasileiras S/A. "Aproveitamentos Maremotrizes na Costa do Maranhão, Pará e Amapá-Inventário Preliminar". ELETROBRÁS. 1981.

[39] Zoneamento Ecológico do Estado do MaranhãoZEEMA. "Fotos Aéreas-São Luís". 1999. Date of visit: 19 de abril de 2011.

URL: www.zee.ma.gov.br 